\title{
CONTAMINAÇÃo DE ÁGUAS POR BTXS E PROCESSOS UTILIZADOS NA REMEDIAÇÃO DE SÍTIOS CONTAMINADOS
}

\author{
Elaine Regina Lopes Tiburtius e Patricio Peralta-Zamora*
}

Departamento de Química, Universidade Federal do Paraná, CP 19081, 81531-990 Curitiba - PR

Elenise Sauer Leal

Centro Federal de Educação Tecnológica, CP 20, 84016-210 Ponta Grossa - PR

Recebido em 12/3/03; aceito em 9/10/03

\begin{abstract}
CONTAMINATION OF WATERS BY BTXS AND PROCESSES USED IN THE REMEDIATION OF CONTAMINATED SITES. After decades of polluting actions the environment manifests serious and global consequences. The contamination of soils and groundwater by organic compounds is a widespread problem mainly on account of contamination by leakage from underground storage tanks, which often results in the release of gasoline or other chemicals. The main problem about groundwater contamination is due to the toxicity of water-soluble components such as benzene, toluene and xylene (BTX). In the present work a study about classical and modern methods for remediation of BTX is reported.
\end{abstract}

Keywords: BTXs; water contamination; remediation.

\section{INTRODUÇÃO}

Nas últimas décadas, o aumento populacional e o conseqüente aumento das atividades industriais vêm contribuindo para o agravamento dos problemas ambientais, principalmente com respeito à preservação das águas superficiais e subterrâneas. Em função deste fato, a legislação vem se tornando cada vez mais restritiva e a fiscalização, mais presente. Entretanto, relatos de despejos de toneladas de resíduos em córregos, rios e mares são ainda bastante freqüentes em todo o mundo.

No Brasil, a realidade não é diferente. Segundo o relatório apresentado em 2001 pela Agência Nacional de Águas, cerca de 70\% dos rios que fazem parte das bacias hidrográficas que vão do Sergipe ao Rio Grande do Sul apresentaram altos índices de contaminação, principalmente por efluentes urbanos, substâncias lixiviadas de grandes lixões e agrotóxicos ${ }^{1}$.

Normalmente, uma importante parcela do processo de contaminação pode ser atribuída às atividades das refinarias de petróleo e seus derivados ${ }^{2}$. O relatório da comissão mista para analisar o acidente na Petrobrás/Repar (CREA-PR) cita 33 acidentes ocorridos com derramamento de petróleo e seus derivados, no Brasil, no período de 1975 a 2001, somando milhões de litros que contaminaram solos, rios e mar. Um dos acidentes mais recentes ocorreu em julho de 2000, durante a operação de transferência de petróleo do terminal São Francisco do Sul, litoral de Santa Catarina, para a refinaria de Araucária. Cerca de 4 milhões de litros de petróleo atingiram os rios Barigüi e Iguaçu. Após o evento, concentrações elevadas de benzeno, tolueno, etil-benzeno, xilenos e naftaleno foram detectadas, o que provocou significativos danos à flora e fauna aquáticas e sério risco à população humana ali residente 3 .

A contaminação de águas subterrâneas por compostos orgânicos deste tipo representa também sérios problemas à saúde pública. As espécies benzeno, tolueno e xilenos (BTXs) são freqüentemente encontradas em águas subterrâneas, por causa de vazamentos em tanques de estocagem ${ }^{4-6}$.

\footnotetext{
*e-mail: zamora@quimica.ufpr.br
}

\section{CONTAMINAÇÃO POR BTXS}

Vazamentos em postos de combustíveis provocam graves problemas ao meio ambiente, principalmente com respeito a contaminação de águas subterrâneas ${ }^{7}$. Para se ter uma idéia do problema, a Agência de Proteção Ambiental Norte Americana (EPA) estima que existem mais de 1,5 milhões de tanques subterrâneos de armazenamento de gasolina nos Estados Unidos. Destes, 400.000 já foram substituídos ou adaptados de acordo com as legislações federais. Mesmo assim, mais de 250.000 casos de vazamentos já foram identificados e mais de 97.000 ações remediadoras foram implementadas. Semanalmente, mais de 1.000 novos vazamentos estão sendo encontrados em todo o território norte-americano ${ }^{4,8,9}$.

No Brasil, existem cerca de 27.000 postos de combustíveis, os quais podem provocar impacto sobre os recursos aquáticos, principalmente envolvendo águas subterrâneas. Ainda não existem estatísticas sobre a magnitude do problema da contaminação por BTX. Entretanto, em função de muitos tanques terem mais de 25 anos de uso, acredita-se que a possibilidade de ocorrerem vazamentos é extremamente grande, principalmente pelo surgimento de rachaduras ou corrosão ${ }^{10,11}$.

Manzochi ${ }^{12}$ acompanhou as atividades operacionais de abastecimento e descarga de combustíveis, troca de óleo e lavagem de veículos em um posto de abastecimento de combustíveis de Florianópolis (SC). Ele alerta que, carregado pela chuva, o material derramado pode contaminar o solo e a água, atingindo rios, lençóis freáticos e galerias pluviais. Considerando o vazamento de $10 \mathrm{~mL}$ por dia, durante um ano, estima-se que pode haver comprometimento de $3 \mathrm{mi}-$ lhões de litros de água. A extensão da contaminação depende do vazamento e das condições do local onde o posto está instalado (tipo do solo). Salienta ainda que a contaminação do solo e da água pode trazer graves conseqüências, inclusive riscos à saúde pública, principalmente em áreas urbanas. Exemplos citados são as cidades de Cascavel e Campo Largo (PR), que tiveram durante 2001 o abastecimento de água suspenso, devido à contaminação dos mananciais fornecedores por postos de combustível da região.

Segundo o geólogo Petrick ${ }^{12}$, a preocupação com acidentes nos postos está aumentando no Brasil. As principais causas de vazamen- 
tos apontadas por este são falha humana durante a descarga do combustível e defeitos na estrutura do tanque. Segundo Petrick, o número de postos que apresentaram problemas varia de 20 a $30 \%$ no Brasil, sendo que na maioria dos casos, só se perceberam os vazamentos depois da descoberta dos seus efeitos.

O maior problema da contaminação por gasolina está relacionado com hidrocarbonetos aromáticos, dentre os que se destacam benzeno, tolueno e xilenos (BTX) ${ }^{13}$. Os compostos aromáticos (BTX e outros alquilbenzenos) perfazem cerca de 10 a $59 \%$ da gasolina (massa/massa), enquanto que os hidrocarbonetos alifáticos compreendem 41 a $62 \%$. Os hidrocarbonetos aromáticos são geralmente mais tóxicos que os compostos alifáticos com o mesmo número de carbonos e possuem maior mobilidade em água, em função da sua solubilidade em água ser da ordem de 3 a 5 vezes maior (Tabela 1). Hidrocarbonetos aromáticos têm também maior mobilidade em sistemas solo-água, característica que pode ser representada significativamente pelo menor coeficiente de partição entre octanol-água (Tabela 1). Um menor coeficiente de partição implica em uma lenta absorção no solo e, conseqüentemente, um transporte preferencial via água. Além de migrarem mais rapidamente através das águas atingindo mananciais de abastecimento, os compostos aromáticos apresentam uma toxicidade crônica mais significativa do que os hidrocarbonetos alifáticos ${ }^{14}$.

Tabela 1. Parâmetros físico-químicos de importância para a mobilidade de hidrocarbonetos. Adaptada da ref. 14

\begin{tabular}{lcc}
\hline Composto & Solubilidade em água $(\mathrm{mg} / \mathrm{L})^{{ }^{a}}$ & $\operatorname{Log~K}_{\text {ow }}^{\mathrm{a}}$ \\
\hline Benzeno & 1760 & 2,12 \\
Tolueno & 532 & 2,73 \\
Xileno & $163-185$ & $2,95-3,26$ \\
Nonano & 0,122 & 4,67 \\
Decano & 0,021 & 6,69 \\
Dodecano & 0,005 & 7,24 \\
\hline
\end{tabular}

$\mathrm{K}_{\mathrm{ow}}$ : coeficiente de partição octanol-água

Experiências têm demonstrado que diferentes formulações na gasolina podem afetar o destino e transporte dos BTXs. O uso do etanol como ingrediente na formulação da gasolina tem aumentado mundialmente, com o intuito de minimizar a poluição atmosférica oriunda da combustão ${ }^{11,15}$. No Brasil, por exemplo, a gasolina é aditivada com aproximadamente (20-25\%) de etanol ${ }^{15}$, fato que aumenta consideravelmente a probabilidade de contaminação de águas subterrâneas por BTX. O etanol é completamente miscível em água o que faz com que, por efeito de co-solvente, aumente a solubilização e migração de BTX $^{11}$.

\section{TOXICIDADE DOS BTXs}

O caráter tóxico do benzeno está relacionado diretamente com o seu potencial carcinogênico e mutagênico ${ }^{15-17}$. Investigações ocupacionais em diferentes indústrias mostram que o benzeno desempenha um indubitável papel de risco aos humanos ${ }^{18}$. Bono et al..$^{19}$, investigando a poluição de aromáticos no ar, destacam que os hidrocarbonetos aromáticos provocam danos à saúde, principalmente devido à toxicidade e/ou mutagenicidade ou carcinogenicidade do BTX. Também advertem que a inalação de tolueno ou xilenos pode induzir distúrbios no modo de falar, na visão, audição, no controle dos músculos e outros, além de sugerirem a associação entre benzeno e xilenos e o surgimento de tumores cerebrais.

A "Internation Agency for Research on Câncer" (Agência Internacional de Pesquisa de Câncer, da Organização Mundial da Saúde, com sede em Lyon, França) e o "National Institute for Ocupational Safety and Health" (Agência Norte-Americana de Saúde e Segurança Ocupacional) incluem o benzeno em suas listas de produtos cancerígenos. Dentre os cânceres, as leucemias são as mais freqüentes e, dentre elas, as mais comuns são as agudas. No Brasil, a ação cancerígena do benzeno foi também reconhecida oficialmente a partir de 1994, pela portaria da Secretaria de Segurança e Saúde no Trabalho (SSST n⿳3), de 10 de março de 199420. A sua capacidade em provocar danos cromossômicos e à medula óssea já foram amplamente demonstradas em seres humanos e animais. Foram observadas alterações cromossômicas numéricas e estruturais em linfócitos e células da medula óssea de trabalhadores expostos ao benzeno ${ }^{21}$.

Damas et al. ${ }^{22}$, em seu trabalho sobre os efeitos tóxicos das marés negras sobre a fauna marinha, fizeram menção aos efeitos danosos do benzeno, tolueno e xilenos ao organismo humano e de outros seres vivos. As doses tóxicas são de 10 a 90 ppm para o benzeno e 4 a 5 ppm para o naftaleno. Estes poluentes influenciam sistemas endócrinos e enzimáticos, além de que hidrocarbonetos ingeridos por organismos marinhos passam através da parede intestinal e se tornam parte da reserva lipídica. Quando dissolvidos no tecido adiposo, os hidrocarbonetos são preservados, porque estão protegidos do ataque microbiano, podendo ser transferidos da presa para o predador e, eventualmente, ao homem. A exposição prolongada a concentrações sub-letais de poluentes pode tornar o organismo mais susceptível às doenças. Aparecimento de tumores, alterações genéticas e leucemias são algumas conseqüências clínicas da intoxicação por hidrocarbonetos.

Quando hidrocarbonetos aromáticos são incorporados pela flora e fauna, ligam-se às moléculas protéicas e ao tecido gorduroso, sendo transferidos através da cadeia alimentar sem alterações da estrutura. Muitos seres expõem-se à contaminação por hidrocarbonetos derivados do petróleo por ingestão de cadáveres, ou de outros animais ou plantas que tenham acumulado hidrocarbonetos no seu organismo, em quantidades insuficientes para causar lesão. Isto traz sérias implicações para a pesca e a saúde pública ${ }^{22}$

Em função destes fatores a legislação tem se tornado cada vez mais restritiva ${ }^{23}$. A Agência de Proteção Ambiental Norte Americana (EPA), por exemplo, estabelece os limites máximos para a concentração do benzeno em $5 \mu \mathrm{g} / \mathrm{g}$ em água potável ${ }^{8}$. No Brasil, a portaria $\mathrm{n}^{\circ} 1469 / 2000$ do Ministério da Saúde determina que os limites máximos permitidos para benzeno, tolueno e xilenos são de 5;170 e $300 \mu \mathrm{g} / \mathrm{L}$, respectivamente, para que a água seja considerada potável ${ }^{24}$.

\section{TRATAMENTO DE SÍTIOS CONTAMINADOS}

\section{Processos físicos e químicos}

A forma mais comum e amplamente usada na remediação de águas subterrâneas contaminadas por compostos voláteis consiste em um tratamento denominado "pump and treat" 25 . Neste procedimento, a água contaminada por poluentes orgânicos é retirada por bombeamento, submetida a um processo de remoção de poluentes e descarregada, às vezes, de volta ao reservatório natural (Figura 1) ${ }^{26}$. Normalmente, as técnicas utilizadas na depuração da água correspondem a processos de "air striping" e extração por adsorção em carvão ativado. Embora eficientes, estes processos apresentam serias limitações, principalmente relacionadas com o seu caráter não destrutivo. Enquanto a remoção de voláteis por "air stripping" implica na liberação de gases poluentes para a atmosfera, o processo de adsorção leva à geração de fases sólidas saturadas com contaminantes não-destruídos. Adicionalmente, a necessidade de associar diversas tecnologias de tratamento faz com que os processos se tornem de- 
morados e dispendiosos, principalmente pela complexidade das instalações.

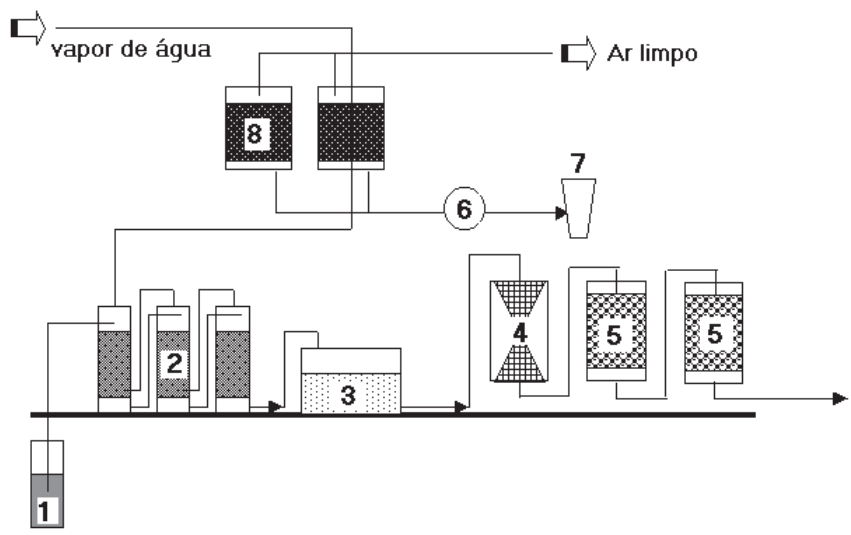

Figura 1. Esquema do processo de recuperação de água subterrânea: 1: poço de retirada da água, 2: colunas de "stripping", 3: bioreator, 4: filtro de cascalho, 5: filtro de carvão ativado (úmido), 6: condensador, 7: separador, 8: filtro de carvão ativado. Adaptada da ref. 26

Processos fundamentados em "air stripping" são muito utilizados em instalações petroquímicas. A metodologia, que envolve a injeção de ar para dentro do aquíf́ero contaminado, a transferência dos contaminantes voláteis para a fase gasosa e sua separação por um sistema de extração de vapor, apresenta baixa eficiência para a remoção de espécies de caráter fenólico, usualmente de maior solubilidade em água.

Outro processo utilizado para descontaminação é a oxidação catalítica. Neste, o ar é aquecido à $300-500{ }^{\circ} \mathrm{C}$ por um tempo curto, sobre platina. $\mathrm{O}$ processo é eficiente, embora bastante dispendioso, pelo alto custo de energia para aquecimento de grandes volumes de vapor de água. É importante salientar também que os catalisadores comerciais utilizados na oxidação de compostos voláteis são, na sua maioria, à base de metais nobres, de elevado custo ${ }^{27}$.

Shih et al. ${ }^{28}$ realizaram um estudo para validar e otimizar a capacidade do carvão ativado granulado na remoção de MTBE (metilterc-butil éter), na presença de competidores como matéria orgânica e compostos orgânicos voláteis presentes na gasolina (ex: benzeno, tolueno e xilenos). O estudo constatou que a competitividade de adsorção de MTBE e BTX causa uma diminuição da ordem de $30 \%$ na capacidade de remoção do carvão ativado.

A associação de um processo físico e térmico foi proposta por Chih-Ju et al. ${ }^{29}$. Neste trabalho, a extração com carvão ativado granulado, seguida de tratamento por microondas, leva à geração de uma chama vermelha com temperaturas de, aproximadamente, 1200 a $1800{ }^{\circ} \mathrm{C}$

\section{Processos biológicos}

A biorremediação é o processo mais utilizado na degradação de BTX. Este processo fundamenta-se na oxidação biológica por microorganismos, decompondo a matéria orgânica em substâncias mais simples como $\mathrm{CO}_{2}$ e $\mathrm{H}_{2} \mathrm{O}$ ( ou $\mathrm{CH}_{4}$ e $\mathrm{CO}_{2}$ ), com custos relativamente baixos. A capacidade de certos microorganismos para degradar substâncias orgânicas tóxicas é um fato bem documentado ${ }^{30-32}$. Pesquisas desenvolvidas em regiões frias ou temperadas mostraram que diversos grupos de bactérias e fungos têm habilidade para degradar componentes do petróleo ${ }^{33-35}$. A complexidade dos processos metabólicos necessários a essa degradação leva à formação de consórcios, com bactérias de diferentes gêneros e espécies, cada uma especializada em degradar uma ou várias frações do óleo derrama$\mathrm{do}^{36}$. A grande motivação de todos os pesquisadores envolvidos em estudos de biodegradação é, sem dúvida, a busca de microorganismos versáteis capazes de degradarem, de maneira eficiente, uma grande variedade de poluentes a baixo custo operacional ${ }^{37}$.

O benzeno é um dos hidrocarbonetos aromáticos mais difíceis de degradação sob condições anóxidas. A deslocalização da nuvem de elétrons estabiliza as ligações carbono-carbono, tornando o benzeno altamente resistente ao ataque. Embora um grande número de artigos relate a degradação anaeróbia de outros hidrocarbonetos aromáticos, dentre eles tolueno e xilenos, muitas investigações têm descrito o benzeno como recalcitrante ${ }^{38}$.

Estudos sobre a biodegradação de poluentes voláteis - como benzeno, tolueno e xilenos - em reatores seqüenciais anóxidos/ microaeróbios têm mostrado que tolueno e p-xilenos são tratáveis sob condições anóxidas (nitrificação), enquanto benzeno, orto e paraxilenos somente são biodegradáveis sob condições microaeróbias ${ }^{39}$.

Keller et $a l .{ }^{40}$ alertam que a contaminação de lençóis aqüíferos causada por tanques subterrâneos de estocagem de gasolina tem sido uma preocupação mundial. Para aumentar as dificuldades, diferentes compostos oxigenados são adicionados à gasolina, com o objetivo de diminuir a emissão de monóxido de carbono. A presença de espécies como etanol e metil-terc-butil éter (MTBE) costuma dificultar, de maneira significativa, a biorremediação dos resíduos, em função da baixa biodegradabilidade.

A biodegradação de BTX em sistemas aeróbios e anaeróbios foi investigada, com respeito à presença de etanol na gasolina, por Corseuil et al. ${ }^{11}$. Os estudos demonstraram que em condições aeróbias o etanol retarda a biodegradação de BTX, devido à utilização preferencial de etanol pelos microorganismos. O benzeno mostra-se recalcitrante em condições de nitrificação, sulfonogênicas e metanogênicas, em um período de 99 dias de incubação. Este fato é particularmente importante, já que benzeno é o mais tóxico dos BTXs.

Uma nova abordagem para a descontaminação de solos e águas subterrâneas, chamada de remediação natural, vem ganhando aceitação nos últimos anos, principalmente em locais contaminados por derramamentos de derivados de petróleo. A atenuação natural refere-se aos processos físicos, químicos e biológicos que facilitam a remediação natural. Este processo limita bastante o deslocamento dos contaminantes e, portanto, reduz a extensão da contaminação no meio ambiente .

Vermace et $a l .{ }^{41}$ investigaram a utilização de nitrato para a estimulação de um consórcio de microorganismos endógenos na degradação de BTX. O estudo constata que a adição deste nutriente efetivamente eleva a concentração de microorganismos, fato que facilita a biorremediação dos poluentes.

A biorremediação natural tem tido grande progresso no norte da América e Europa. Apesar disto, as experiências têm demonstrado que a adequação deste método no Brasil precisa de muito cuidado, em decorrência da presença de etanol como constituinte da gasoli$\mathrm{na}^{10}$. Estudos para avaliar a atenuação natural em derramamentos de gasolina contendo etanol, diesel puro e diesel com etanol estão sendo realizados na Fazenda Experimental da Ressecada, em Florianópolis-SC. Os resultados demonstraram que a atenuação reduz o potencial de contaminação dos locais onde ocorreram derramamentos de gasolina, principalmente pelo efeito de degradação biológica, que transforma espécies poluentes em compostos inócuos à saúde humana. Contudo, as plumas de contaminação desapareceram somente após 1000 dias de tratamento ${ }^{42}$.

Venkatraman et al. ${ }^{5}$ realizaram estudos sobre biorremediação in situ, promovendo o processo por adição de fosfato, nitrato e sais de amônia. Os resultados indicaram uma redução da ordem de $85 \%$ no teor de BTXs, após um período de 50 semanas. 


\section{Processos oxidativos avançados}

As regulamentações relacionadas com a qualidade das águas vêm se tornando cada vez mais restritivas, principalmente em função da constatação definitiva da vulnerabilidade deste recurso essencial ${ }^{43}$. Em função de ineficiência, elevado custo e complexidade operacional dos tratamentos existentes no momento, as tecnologias alternativas têm recebido bastante atenção nos últimos anos. Dentro deste contexto, o tratamento de poluentes orgânicos recalcitrantes por Processos Oxidativos Avançados (POAs) tem se mostrado uma alternativa bastante promissora ${ }^{2}$.

Os POAs têm como principal característica a geração de radicais hidroxilas (HO), que reagem rápida e indiscriminadamente com muitos composto orgânicos, ou por adição à dupla ligação ou por abstração do átomo de hidrogênio em moléculas orgânicas alifáticas. O resultado é a formação de radicais orgânicos que reagem com oxigênio, dando início a uma série de reações de degradação que podem culminar em espécies inócuas, tipicamente $\mathrm{CO}_{2} \mathrm{e}_{2} \mathrm{O}^{44}$. Vários processos de produção do radical hidroxila têm sido estudados, geralmente utilizando ozônio, peróxido de hidrogênio, semicondutores e reagente de Fenton ${ }^{2}$.

\section{Fotólise}

A potencialidade da radiação ultravioleta tem sido avaliada extensamente na remediação de resíduos, principalmente visando a sua desinfecção ${ }^{45}$. Em função da elevada eficiência da radiação UV na destruição de microorganismos, muitos equipamentos fundamentados na utilização de lâmpadas a vapor de mercúrio foram comercializados, principalmente para servirem de alternativa à desinfecção química.

Nos últimos anos, pesquisadores têm estendido a aplicação desta tecnologia para o tratamento de compostos orgânicos voláteis ${ }^{46}$. $\mathrm{Na}$ fotólise direta, moléculas orgânicas podem absorver fótons de radiação ultravioleta, gerando espécies eletronicamente excitadas que podem transferir elétrons para aceptores presentes no meio, formando radicais livres. Estas espécies radicalares podem reagir com oxigênio molecular, gerando radicais peroxi que tendem a se decompor naturalmente, formando intermediários parcialmente oxidados.

Em geral, a fotodegradação em fase gasosa é mais atrativa que em fase líquida, devido à baixa absorção UV pelo ar, à presença de oxigênio e à ausência de seqüestradores de radicais, como os íons carbonato e bicarbonato ${ }^{47}$.

Wang et al..$^{48}$ avaliaram a eficiência da luz ultravioleta e do processo UV/ $\mathrm{H}_{2} \mathrm{O}_{2}$ na degradação de poluentes orgânicos em efluentes. Os resultados demonstraram que apenas a luz UV não foi suficiente para a degradação das espécies em estudo. Em geral, a adição de uma pequena quantidade de peróxido de hidrogênio aumenta significativamente a taxa de oxidação dos compostos orgânicos estudados.

\section{Ozônio/UV}

Quando associado à radiação ultravioleta, o poder oxidante de ozônio aumenta significativamente, em função da geração do forte oxidante radical hidroxila (Equações 1 e 2$)^{49}$.

$\mathrm{O}_{3}+\mathrm{hv} \rightarrow \mathrm{O}^{*}+\mathrm{O}_{2}$

$\mathrm{O}^{\bullet}+\mathrm{H}_{2} \mathrm{O} \rightarrow 2 \cdot \mathrm{OH}$

Recentemente, alguns pesquisadores têm proposto a utilização deste sistema para degradação de compostos orgânicos voláteis, em fase gasosa ${ }^{50,51}$. Entretanto, a utilização desta técnica na destruição de poluentes voláteis em fase aquosa está sujeita a um fator limitante, representado pela libertação das moléculas voláteis da solução por adição de $\mathrm{O}_{3}$, de forma similar à prática de "ar stripping".

\section{Fotocatálise heterogênea}

Dentro do contexto dos POAs, a fotocatálise heterogênea pode ser considerada uma técnica clássica, a partir da qual grande parte dos conceitos envolvidos nos processos oxidativos avançados foram elucidados. A degradação de compostos orgânicos através de fotocatálise heterogênea, assim como os princípios que fundamentam o processo têm sido bastante documentados ${ }^{52-56}$.

A fotocatálise heterogênea envolve a ativação de um semicondutor (geralmente $\mathrm{TiO}_{2}$ ) por luz solar ou artificial. Um semicondutor é caracterizado por bandas de valência (BV) e bandas de condução (BC), sendo a região entre elas chamadas de "band gap". A absorção de fótons com energia superior à energia do "band gap" resulta na promoção de um elétron da banda de valência para a banda de condução, com geração concomitante de uma lacuna $\left(\mathrm{h}^{+}\right)$na banda de valência. Estas lacunas mostram potenciais bastante positivos, na faixa de $+2,0$ a 3,5 eV. Este potencial é suficientemente positivo para gerar radicais hidroxilas $\mathrm{HO}$, a partir das moléculas de água adsorvidas na superfície do semicondutor (Equações 3 e 4), os quais podem subseqüientemente oxidar o contaminante orgânico ${ }^{57}$.

$\mathrm{h}^{+}+\mathrm{H}_{2} \mathrm{O}_{\text {ads. }} \rightarrow \mathrm{OH}^{\cdot}+\mathrm{H}^{+}$
$\mathrm{h}^{+}+\mathrm{OH}_{\text {ads. }}^{-} \rightarrow \mathrm{OH}^{\cdot}$

Dentro do contexto das espécies químicas relacionadas com o tipo de contaminação aqui tratado, a fotocatálise heterogênea tem sido utilizada com bastante sucesso na degradação de inúmeros substratos de interesse, utilizando-se principalmente $\mathrm{TiO}_{2}$ como catalisador (Tabela 2). Estes estudos demonstram uma baixa seletividade oxidativa do radical hidroxila e, portanto, uma boa potencialidade para a degradação de BTXs.

Tabela 2. Degradação de substratos de interesse via fotocatálise heterogênea

\begin{tabular}{ll}
\hline Espécie Química & Sistema \\
\hline BTX & $\mathrm{TiO}_{2}$ imobilizado $^{26}$ \\
Benzeno & $\mathrm{TiO}_{2}$ imobilizado $^{58}$ \\
Benzeno & $\mathrm{TiO}_{2}$ imobilizado $^{59}$ \\
Benzeno & $\mathrm{TiO}_{2}$ imobilizado $^{60}$ \\
Benzeno & $\mathrm{TiO}_{2}$ imobilizado $^{61}$ \\
Tolueno & $\mathrm{TiO}_{2}$ imobilizado $^{62}$ \\
Tolueno & $\mathrm{TiO}_{2}$ e Pt/TiO \\
Tolueno & $\mathrm{TiO}_{2}^{64}$ \\
Tolueno & $\mathrm{TiO}_{2}-\mathrm{H}_{2} \mathrm{O}_{2}\left(\right.$ fase vapor $^{65}$ \\
Tolueno & $\mathrm{Adsorção-TiO}_{2}^{66}$ \\
\hline
\end{tabular}

Métodos heterogêneos orientados para a remediação de efluentes industriais, ou pelo menos para substratos de interesse ambiental, são abundantes. Entretanto, a aplicação destes procedimentos em níveis industriais é bastante discutida, principalmente em função de desvantagens que derivam do seu caráter heterogêneo. Neste sentido, a dificuldade na penetração da radiação em um meio que contém uma fina suspensão de partículas opacas e a dificuldade na remoção dos fotocatalisadores, uma vez terminado o processo, constituem-se nas principais desvantagens destes métodos. Com o intuito de con- 
tornar estes problemas, muitos trabalhos sobre imobilização de semicondutores, em suportes como zeólitas, cerâmicas, sílicas, vidros, polímeros e outros, têm sido desenvolvidos ${ }^{67-69}$.

\section{Processos oxidativos avançados envolvendo $\mathrm{H}_{2} \mathrm{O}_{2}$}

O radical hidroxila, principal agente oxidante nos processos denominados "Oxidativos Avançados", pode ser gerado com eficiência a partir de sistemas que envolvam radiação ultravioleta e peróxido de hidrogênio (Equação 5).

$\mathrm{H}_{2} \mathrm{O}_{2}+\mathrm{hv}(254 \mathrm{~nm}) \rightarrow 2 \mathrm{HO}^{\bullet}$

A elevada eficiência de degradação dos sistemas fotoquímicos assistidos por $\mathrm{H}_{2} \mathrm{O}_{2}$ tem sido bastante documentada. Dentre os resultados importantes destacam-se a completa e rápida degradação de 1,4-dioxano ${ }^{70}$, pentaclorofenol ${ }^{71}$, 2-clorobifenil ${ }^{72}$ e fenol $^{73}$.

A degradação eficiente de espécies orgânicas presentes em águas residuais de refinarias e em outros efluentes da indústria petroquímica foi reportada recentemente ${ }^{74,75}$. Em geral, admite-se que o sistema $\mathrm{UV} / \mathrm{H}_{2} \mathrm{O}_{2}$ apresenta uma excelente potencialidade como tratamento terciário, promovendo a fragmentação de espécies recalcitrantes.

O radical hidroxila também pode ser gerado através da reação de Fenton (Equação 6), processo que tem permitido a degradação eficiente de poluentes ${ }^{76,77}$.

Diversos trabalhos utilizando o processo Fenton para a degradação de espécies de interesse ambiental são relatados na literatura. Dentre outros, é possível destacar a mineralização eficiente de hidrocarbonetos aromáticos policíclicos em solos contaminados ${ }^{78}$. O mesmo substrato foi estudado por Kyoungphile et al..$^{79}$, utilizando um processo integrado (biodegradação/Fenton). Os resultados demonstraram que a biodegradação seguida do processo Fenton é mais eficiente que o processo inverso. A utilização de óxidos minerais, como por exemplo goetita, como catalisador de Fenton, aparece como uma nova alternativa para a degradação de diversos poluentes orgânicos ${ }^{80}$.

Lou et $a l .^{81}$, estudando a oxidação de benzeno, tolueno e xilenos através do processo Fenton, observaram a rápida degradação destes substratos, de modo geral, em tempos inferiores a $10 \mathrm{~min}$.

Recentemente, melhoras importantes na eficiência do processo têm sido reportadas, recorrendo-se à utilização de sistemas assistidos por radiação ultravioleta (Equação 7).

Este aumento na eficiência da reação é atribuída à geração de quantidades adicionais de radical hidroxila, por fotoredução de íons férricos formados durante a reação de Fenton. A fotoredução leva à regeneração dos íons ferrosos, o que fecha o ciclo catalítico ${ }^{82,83}$.

$\mathrm{Fe}^{2}++\mathrm{H}_{2} \mathrm{O}_{2} \rightarrow \mathrm{Fe}^{3+}+\mathrm{OH}^{-}+\mathrm{HO}^{\cdot}$

$\mathrm{Fe}^{3+}+\mathrm{H}_{2} \mathrm{O} \rightarrow \mathrm{Fe}^{2+}+\mathrm{H}^{+}+\mathrm{HO}^{\circ}$

Entre outros estudos importantes, destacam-se a degradação de pesticidas $^{84-86}$, hidrocarbonetos aromáticos ${ }^{87}$, policíclicos aromáticos ${ }^{88}$ e poluentes fenólicos ${ }^{89}$.

Certamente, uma das principais vantagens do sistema Fenton fotoassistido está representada pela necessidade de fontes de irradiação menos energéticas. Enquanto a geração de radical hidroxila a partir de $\mathrm{H}_{2} \mathrm{O}_{2}$ requer energia correspondente a comprimentos de onda da ordem de $254 \mathrm{~nm}$, o sistema foto-Fenton pode se processar com radiação visível $(410 \mathrm{~nm})^{84}$.

O processo de geração de radicais hidroxilas por fotólise UVVIS (fonte de luz de baixa pressão de mercúrio com emissão de 200 a $600 \mathrm{~nm}$ ) e ferrioxalato na presença de peróxido de hidrogênio (UVVIS/ferrioxalato/ $\mathrm{H}_{2} \mathrm{O}_{2}$ ) foi investigado no tratamento de água conta- minada e em efluentes industriais, por Safarzadeh-Amiri ${ }^{37}$. Água contendo poluentes orgânicos (clorobenzeno, mistura de BTXs, metanol, formaldeído e ácido fórmico) foi tratada com sucesso pelo sistema, indicando um bom potencial de aplicação no tratamento de águas com alto grau de contaminação.

Keller et $a l .{ }^{40}$, utilizando um dos processos de geração de radicais hidroxilas com $\mathrm{O}_{3}$ e $\mathrm{O}_{3} / \mathrm{H}_{2} \mathrm{O}_{2}$, demonstraram a capacidade deste procedimento de remover MTBE da água, indicando o uso do $\mathrm{O}_{3}$ como uma tecnologia de remediação viável para águas subterrâneas contaminadas.

Watts et al. ${ }^{14}$ avaliaram a oxidação de hidrocarbonetos aromáticos e alifáticos da gasolina, utilizando um processo Fenton modificado. Os resultados indicaram que benzeno, tolueno e xilenos foram efetivamente oxidados em baixas concentrações, sugerindo este processo como um tratamento economicamente viável.

\section{CONSIDERAÇÕES FINAIS}

Entre todos os problemas provocados pelo fenômeno de poluição ambiental, a contaminação das águas, e a conseqüente escassez de recursos hídricos de boa qualidade, talvez seja um dos mais importantes. Dentro deste contexto, a contaminação por petróleo e derivados tem causado bastante preocupação, seja pela freqüência dos eventos ou pelo elevado potencial poluente dos mesmos.

Muitas alternativas têm sido propostas para a remediação de sítios contaminados com este tipo de resíduos. As desvantagens particulares de cada uma delas têm promovido o surgimento de novas propostas, algumas bastante promissoras. Dentro deste grupo de tecnologias alternativas destacam-se os processos oxidativos avançados, os quais, em função da elevada eficiência de degradação frente a inúmeros substratos ditos recalcitrantes, representam uma sólida alternativa para a mitigação de problemas tão freqüentes.

Entre as várias alternativas oxidativas avançadas disponíveis, pode ser dado destaque especial aos sistemas Fenton. Trata-se de sistemas que, em função da sua natureza homogênea, são de fácil implementação, mesmo para a remediação de matrizes complexas, como solos. Neste caso particular, a presença de espécies férricas, mesmo óxidos, permite a aplicação de sistemas Fenton, apenas por adição de peróxido de hidrogênio.

\section{REFERÊNCIAS}

1. http://www.ana.gov.br/diadaagua/relatorios.pdf, acessada em Fevereiro 2002.

2. Freire, S. R.; Pelegrine, R.; Kubota, L.; Duran, N.; Peralta-Zamora, P.; Quim. Nova 2000, 23, 504.

3. http://inscut.org.br/aurac5c35alria.rtf, acessada em Janeiro 2002.

4. Mohammed, N.; Allayla, R. I.; J. Hazard. Mater. 1997, 54, 155.

5. Venkatraman, S. N.; Boland, T. M.; Bossert, I. D.; Kasson, D. S.; J. Soil Contamin. 1998, 7, 143.

6. Costura, R. K.; Alvarez, P. J.; Water Res. 2000, 34, 3014.

7. Prommer, H. ; Barry, D. A.; Davis, G. B.; Environ. Model. Softw. 1999, 14, 213.

8. Gerlach, R. W.; White, R. J.; Deirdre O'Leary, N. F.; Van Emon, J. M.; Water Res. 1997, 31, 941.

9. Corseuil, H. X.; Marins, M. D. M.; Revista Engenharia Sanitária e Ambiental 1997, 2, 54.

10. Corseuil, H. X.; Alvarez, J. J. P.; Water Sci. Technol. 1996, 34, 311.

11. Corseuil, H. X.; Hunt, S. C.; Santos, F. C. R.; Alvarez, J. J. P.; Water Res. 1998, 32, 2065.

12. Manzochi, C.; Ciência Hoje 2001, 29, 40.

13. Nakhla, G.; Water Res. 2003, 37, 1296.

14. Watts, R. J.; Haller, D. R.; Jones, A. P.; Tell, A. L.; J. Hazard. Mater. 2000, 76,73 .

15. Fernandes, M.; Brickus, L. S. R.; Moreira, J. C.; Cardoso, J. N.; Chemosphere 2002, 47, 417. 
16. Zhihua, Z.; Glott, Q. H.; Plott, K. L.; Goldstein, B. D.; Witz, G.; Free Radical Biol. Med. 1995, 18, 411.

17. Riedel, K.; Ruppert, T.; Conze, C.; Schere, G.; Adekafer, F.; J. Chromatogr. 1996, 719, 383.

18. Römmelt, H.; Pfaller, A.; Fruhmann, G.; Nowak, D.; Sci. Total Environ. 1999, 241, 197.

19. Bono, R.; Bugliosi, H. E.; Schiliró, T.; Gilli, G.; Atmos. Environ. 2001, $35,107$.

20. http//www.mte.gov.br, acessada em Março 2002.

21. http://www.eps.ufs.br/ergon/revista/artigos/Angeliete.pdf, acessada em Março 2002

22. http://www.fmv.utl.pt/democ/sft/sem9900/g004.pdf, acessada em Janeiro 2002.

23. Bilstad, T.; Espedal, E.; Water Sci. Technol. 1996, 34, 239.

24. http//www.funasa.gov.br/pub28.htm, acessada em Julho 2003.

25. Jiang, J-S.; Vone, L. M.; Sikdar, S. K.; J. Membr. Sci. 1997, 136, 233.

26. Shianetz, B.; Passivos Ambientais, SENAI/ABES: Curitiba 1999, cap. 3.

27. Kim, S. C.; J. Hazard. Mater. 2002, 91, 285.

28. Shih, T. C.; Wangpaichtr, M. S.; Water Res. 2003, 37, 375.

29. Chih-Ju, G. J.; Tai, H. S.; Chemosphere 1998, 37, 685.

30. Uzura, T.; Katsuragi, T.; Tani, Y.; J. Biosci. Bioeng. 2001, 92, 381.

31. Koller, G.; Möder, M.; Czihal, K.; Chemosphere 2000, 41, 1827.

32. Juhasz, A. L.; Naidu, R.; Int. Biodeter. Biodegrad. 2000, 45, 57.

33. Mills, M. A.; Bonner, J. S.; Mc Donald, T. J.; Page, C. A.; Autenrieth, R. L.; Mar. Pollut. Bull. 2003, 46, 887.

34. Meysami, P.; Baheri, H.; Adv. Env. Res. 2003, 7, 881.

35. Nocentini, M.; Pineli, D.; Fava, F.; Chemosphere 2000, 41, 1115.

36. Crapez, M. A. C.; Borges, A. L. N.; Bispo, M. G. S.; Pereira, D. C.; Ciência Hoje 2002, 30, 32.

37. Kunz, A.; Peralta-Zamora, P.; Moraes, S. G.; Durán, N.; Quim. Nova 2002, 25,78 .

38. Phelps, D. C.; Kazumi, J.; Young, Y. L.; FEMS Microbiol. Lett. 1996, 145, 433.

39. Ma, G.; Love, N. G.; Water Sci. Technol. 2001, 43, 275.

40. http//:www.esm.ucsb.edu/fac_staff/fac/Keller/papers/Abstract14.pdf, acessada em Março 2001.

41. Vermace, M. E.; Christensen, R. F. Parkin, G. F.; Alvarez, P. J. J.; Water Res. 1996, 30, 3139.

42. http://www.remas.ufsc.br/publicacoes2.htm, acessada em Fevereiro 2002.

43. Chamarro, E.; Marco, A.; Esplugas, S.; Water Res. 2001, 35, 1047.

44. Amiri, S. A.; Bolton, R. J.; Cater, R. S.; Water Res. 1997, 31, 787.

45. Backlund, P.; Chemosphere 1992, 25, 1869.

46. Wang, J. H.; Ray, M. B.; Sep. Purif. Technol. 2000, 19, 11.

47. Feiyan, C.; Pehkonem, S. O.; Ray, B. M.; Water Res. 2002, 36, 4203.

48. Wang, G-S.; Chen, U-W.; Kang, S-F.; Sci. Total Environ. 2001, $277,87$.

49. Shen, Y-S.; Ku, Y.; Chemosphere 1999, 38, 1855.

50. Pengyi, Z.; Fuyan, L.; Gang, Y.; Qing, C.; Zhu, W.; J. Photochem. Photobiol. A 2003, 156, 189

51. Sekiguchi, K.; Sanada, A.; Sakamato, K.; Catal. Commun. 2003, 4, 247.

52. Tang, W. Z.; Na, H.; Chemosphere 1995, 31, 4171.

53. Lakshmi, S.; Renganathan, R.; J. Photochem. Photobiol., A 1995, 88, 163.
54. Mills, A.; Le Hunte, S.; J. Photochem. Photobiol., A 1997, 108, 1.

55. Mills, A.; Lee, S-K.; J. Photochem. Photobiol., A 2002, 152, 233.

56. Pirkanniemi, K.; Sillanpää, M.; Chemosphere 2002, 48, 1047.

57. Jardim, F. W.; Nogueira, P. F. R.; Quim. Nova 1998, $21,69$.

58. Hisanaga, T.; Tanaka, K.; J. Hazard. Mater. 2002, 93, 331.

59. Shimizu, K-I.; Kaneko, T.; Fujishima, T.; Kodama, T.; Yoshida, H.; Kitayama, Y.; Appl. Catal., A 2002, 225, 185.

60. Chen, J.; Eberlein, L.; Langfort, H. C.; J. Photochem. Photobiol., A 2002 $148,183$.

61. Hsien, Y-H.; Chang, C-F.; Chen, Y-H.; Cheng, S.; Appl. Catal., B 2001, $31,241$.

62. Bouzaza, A.; Laplanche, A.; J. Photochem. Photobiol., A 2002, 150, 207.

63. Blount, M. C.; Falconer, J. L.; Appl. Catal., B 2002, 39, 39.

64. Muggli, D. S.; Ding, L.; Appl. Catal., B 2001, 32, 181.

65. Martra, S.; Coluccia, L.; Marchese,V.; Augugliaro, V.; Loddo, L.; Palmisano, L.; Sciavello, M.; Catal.Today 1999, 53, 695.

66. Crittenden, J. C.; Suri, R. P. S.; Peram, D. L.; Hand, D. W.; Water Res. 1997, 31,411 .

67. Iliev, V.; Tomava, D.; Bilyarska, L.; Prahov, L.; Petrov, L.; J. Photochem. Photobiol., A 2003, 159, 281.

68. Bowker, M.; James, D.; Stone, P.; Bennett, R.; Perkins, N.; Millard, L.; Greaves, J.; Dickinson, A.; J. Catal. 2003, 217, 427

69. Iannazzo, V.; Neri, G.; Galvagno, S.; Di Serio, M.; Tesser, R.; Santacessaria, E.; Appl. Catal., A 2003, 246, 49.

70. Stefan, M. I.; Bolton, J. R.; Environ. Sci. Technol. 1998, 32, 1588.

71. Te-Fu, L.; Bolton, J.; Water Res. 1998, 32, 489.

72. Wang, Y.; Hong, C. S.; Water Res. 1999, 33, 2031.

73. Martyanov, I. N.; Savinov, E. N.; Parmon, V. N.; J. Photochem. Photobiol., A 1997, 78, 227.

74. Stepnowsk, P.; Siedlecka, E. M.; Behrend, P.; Jastorff, B.; Water Res. 2002, $36,2167$.

75. Juang, L-C.; Tseng, D-H.; Chaur, S.; Water Sci. Technol. 1997, 36, 357.

76. Sedlak, D. L.; Andren, A. W.; Environ. Sci. Technol. 1991, 25, 1419.

77. Arnold, S. M.; Hickey, W. J.; Harris, R. F.; Environ. Sci. Technol. 1995, 29, 2083.

78. Watts, R. J.; Stanton, P. C.; Howsawkeng, J.; Teel, A. L.; Water Res. 2002, 36,4283 .

79. Kyoungphile, N.; Rodriguez, W.; Chemosphere 2001, 45, 11.

80. Andreozzi, R.; D’Apuzzo, A.; Morotta, R.; Water Res. 2002, 36, 4691

81. Lou, J. C.; Lee, S. S.; Hazard. Wastes Hazard. Mater. 1995, 12, 185.

82. Gogate, P. R.; Pandit, A. B.; Adv. Env. Res. 2003, 8, 501.

83. Arslon, I.; Balcioglu, I. A.; Chemosphere 1999, 39, 2767.

84. Huston, P. L.; Pignatello, J. J.; Water Res. 1999, 33, 1238.

85. Sun, Y.; Pignatello, J.; Environ. Sci. Technol. 1998, 32, 1588.

86. Pignatello, J. J.; Sun, Y.; Water Res. 1995, 29, 1837.

87. Bianchi, D.; Bertoli, M.; Tassinari, R.; Ricci, M.; Vignola, R.; J. Mol. Catal. A: Chem. 2003, 204, 419.

88. Lindsey, M. E.; Xu, G.; Lu, J.; Tarr, M. A.; Sci. Total Environ. 2003, 307, 215 .

89. Gernjak, W.; Krutzler, T. Glaser, A.; Malato, S.; Caceres, J.; Bauer, R.; Fernández-Alba, A. R.; Chemosphere 2003, 50, 71. 